Journal of Sustainable Development of Transport and Logistics

journal home page: https://jsdtl.sciview.net

Roy, U., \& Ksaibati, K. (2021). Investigating trends and characteristics of animal-vehicle

crashes in Wyoming. Journal of Sustainable Development of Transport and Logistics, 6(2), 25-

42. doi:10.14254/jsdtl.2021.6-2.2.

\title{
Investigating trends and characteristics of animal-vehicle crashes in Wyoming
}

\author{
Uttara Roy *(D), Khaled Ksaibati **iD \\ ${ }^{*}$ University of Wyoming, \\ 1000 E. University Ave., Laramie, WY 82071 United States \\ Department of Civil and Architectural Engineering, Wyoming Technology Transfer Center, \\ uroy@uwyo.edu \\ ** University of Wyoming, \\ 1000 E. University Ave., Laramie, WY 82071 United States, \\ Department of Civil and Architectural Engineering, Wyoming Technology Transfer Center \\ khaled@uwyo.edu
}

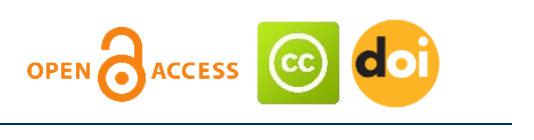

\section{Article history:}

Received: September 15, 2021

1st Revision: September 21, 2021

Accepted: November 16, 2021

\section{DOI:}

10.14254/jsdtl.2021.6-2.2

\begin{abstract}
Animal-vehicle crashes (AVCs) are a severe concern in the United States as well as in Wyoming. This study investigated the current trends of AVCs and crash rate per vehicle miles traveled (VMT) for the State of Wyoming using police-reported crash data for ten years collected from the Wyoming Department of Transportation (WYDOT). The study also examined different driver, vehicular, roadway, and environmental conditions related factors that had a strong association with AVCs. The logistic regression model was developed to check how the factors prevalent in AVCs influence the severity of AVCs. The results showed that the percentage of AVCs to that of total crashes ranged from around $15 \%$ to $22 \%$. Among different animals involved in crashes, the majority were deer. AVCs were found to have two peaks: dawn and dusk. AVC rate was found to be the highest in November. Also, dark and unlit conditions had a strong association with AVCs. Most of the AVCs tended to occur when there were no adverse weather conditions. When the speed limit was examined, it was found that the AVC crash rate tended to increase when the posted speed limit was higher than $60 \mathrm{mph}$. AVC rate was also higher when the road surface condition was dry. Higher posted speed limit, younger drivers, and dry road surface were also found to increase the severity of AVCs. The results identified in this study will be helpful to identify effective countermeasures to reduce AVCs in Wyoming.
\end{abstract}

Keywords: trends of animal-vehicle crashes, temporal patterns, crash characteristics, crash rates

Corresponding author: Uttara Roy

E-mail: uroy@uwyo.edu

This open access article is distributed under a Creative Commons Attribution (CC-BY) 4.0 license. 


\section{Introduction}

Animal-vehicle crashes (AVCs) are roadway safety hazards, and such crashes most of the time are damaging to the struck animals. Around one million wildlife-vehicle collisions occur annually in the United States, and it results in billions of dollars of property damage, personal injuries, and fatalities (Huijser et al. 2008). The count of fatalities incurred in AVCs rose from the mid-1970s to 2007 and settled after that (Insurance Institute for Highway Safety, 2021). Approximately 180 fatal, 13,000 injury and 265,000 property damage only crashes involving animals were reported in 2015 by NHTSA (National Highway Traffic Safety Administration, 2015). The actual number of crashes may be much higher since not all AVCs are reported. Most researchers believe that AVCs are under-reported because of many reasons: crashes that result in less than $\$ 1000$ in property damage are typically excluded in crash databases, sometimes drivers do not report collisions with animals, and law enforcement, natural resource or transportation agencies may not have the resources to collect detailed information on AVCs (Huijser et al. 2008).

The situation in the state of Wyoming is not different from the national picture. The state is home to an abundant amount of big game, including long-distance migratory species such as mule deer, elk, and pronghorn (Rigions et al., 2016). These animals frequently need to cross the highway when they intersect with the animal's habitat patches or its corridors (Chen and $\mathrm{Wu}, 2014$ ). This poses a serious threat both to highway safety and to wildlife. According to the data from the Wyoming Department of Transportation (WYDOT), there were a total of 2,874 AVCs that occurred in 2019, which was 19.29\% of the total crashes in Wyoming. Of those 2,874 crashes, one was fatal, and 78 crashes had different levels of injuries. The majority of AVCs in Wyoming involved deer. The estimated costs per reported collision are $\$ 11,600$ in injury and property damage costs and $\$ 4,000$ in the unclaimed compensation value of each deer being killed, according to WYDOT (Rigions et al., 2016). When this is taken together, it was estimated by WYDOT that injury and damage costs for deer-vehicle collisions in Wyoming result in approximately \$24-29 million per year and an additional \$20-23 million per year because of wildlife costs (Rigions et al., 2016).

Previous studies on AVCs in Wyoming are focused mainly on examining the effectiveness of mitigation strategies to reduce AVCs (Gordon et al., 2001; Dai et al., 2009; Rigions et al., 2019). There are a few studies that examined the characteristics of AVCs, but these studies are either older (Young or Vokurka, 2007) or considering data for a particular section of Wyoming (Becker et al. (2008)). There is no recent study done that illustrates the current trends and characteristics of AVCs in Wyoming. This study, therefore, aims to fill this gap by investigating the current trends and characteristics of AVCs in Wyoming. Understanding trends and characteristics of AVCs is vital in order to develop mitigation strategies which will decrease the number of AVCs as well as morbidity and mortality.

The objective of the study was to investigate the trends of AVCs in Wyoming using the data from WYDOT. Important characteristics such as driver, vehicular, roadway, and environmental conditions related factors associated with AVCs were examined. Finally, statistical tests (logistic regression) were conducted to determine which factors influence the severity of AVCs. To the best of the author's knowledge, this study is the first in Wyoming to examine driver, vehicular, roadway, and environmental conditions related factors associated with AVCs.

The remainder of the paper is organized as follows: Section 2 describes the related studies on AVCs, section 3 mentions the data used in this study, section 4 explains the methodology involved in this study, section 5 describes various drivers, roadways, vehicular and environmental conditions related factors associated with AVCs as well as the statistical test conducted in this study and finally section 6 concludes the study.

\section{Literature review}

There are a few studies done in the U.S. which investigate the trends and characteristics of AVCs. There are a couple of studies that used FARS data to examine annual trends of fatal AVCs in the United States (Khattak, 2003; Sullivan, 2011; Langley et al., 2006). Garret and Conway (1999) explored the characteristics of moose-vehicle collisions in Alaska using the data from 1991-1995. In order to examine the patterns of animal-vehicle collisions in Alabama, Chen and Wu (2014) used the data from the Alabama Department of Transportation for the year 2001-2011. Creech et al. (2019) compared 
temporal and spatial patterns of domestic animal-vehicle collision and wildlife-vehicle collision using ten-year crash data from the state of Montana. Studies were also done internationally to investigate spatial and temporal patterns of AVCs as well as characteristics of AVCs. Gunson et al. (2003) investigated the spatial, temporal, and demographical patterns of wildlife-vehicle collisions in central Canadian Rocky Mountains. The same study also investigated the type of vehicles involved in the wildlife vehicle collisions and the conditions which contributed to injury crashes. Cserkesz and Farkas (2015) examined annual trends of AVCs in Hungary for the year 2000-2010. The study also investigated the relationship between the railway and highway wildlife-vehicle collisions in Hungary. Morelle et al. (2013) examined spatio-temporal patterns of wildlife-vehicle collisions in Wallonia, Belgium using police-reported crash data involving free-ranging animals between 2003 and 2011. Using data from 1994-1998, Eloff and Van Niekerk (2008) examined the temporal patterns of animal-related traffic accidents in South Africa. Rowden et al. (2008) investigated the characteristics of animal-vehicle collisions in Australia. Niemi et al. (2017) examined moose-vehicle collisions in Scandinavian countries: Sweden, Norway, and Finland. In this study, annual and monthly variations of moose-vehicle collisions with or without personal injuries were explored.

Since the majority of AVCs turned out to be PDO crashes, there are many studies done on how to reduce the number of crashes. Wilkins et al. (2019) explored the spatial frequency of AVCs in Texas using the data for seven years. Lao et al. (2011a) developed an animal-vehicle collision model considering animal-vehicle interactions. The authors proposed a vehicle-animal interaction-based probability model which characterizes the responses of drivers and animals as well as the unique impacts of animal habitats on collisions. Using three datasets (deer population counts, deer carcass removal data, and deer-vehicle crash data) from Iowa, Gkritza et al. (2010) developed a negative binomial model for estimating the frequency of deer-vehicle crashes. The same study also developed a Poisson regression model to estimate the frequency of injuries. Jiang et al. (2013) explored the relationship between deer-vehicle crash counts and vehicles miles traveled using the Michigan crash database. Murphy and Xia (2016) established a hierarchical Bayesian model using multivariate Poisson lognormal regression, which explains the relationship between AVCs and contributing factors. Lao et al. (2011b) used two datasets (animal-vehicle collision data and carcass removal data) from the state of Washington during 2002-2006 and developed a diagonal inflated bivariate Poisson regression method.

There are a few studies done both nationally and internationally which seek to identify the hotspots of AVCs. Yang et al. (2019) compared the difference in hotspot identification between carcass removal data and reported AVCs. Both negative binomial data and generalized negative binomial data are applied in this study using the animal collision data collected on ten highways in Washington State. Danks and Porter (2010) identified the spatial clusters of moose-vehicle collisions in western Maine using the data from 1992-2005. In order to identify AVCs hotspots, Bartonička et al. (2018) used the kernel density estimation method for Czech Republic using the data from 2006 to 2011. Bíl et al. (2016) used KDE+ software for selecting and prioritizing AVCs in Czech Republic. Using geographic information system and spatial statistics, Rodríguez-Morales et al. (2013) analyzed temporal, spatial, and spatiotemporal patterns of vehicle crashes involving wild boar and roe deer in Spain for 2006-2010. Bíl et al. (2019) analyzed wildlife-vehicle collision data for Czech Republic using the clustering (KDE+) approach.

There are many studies done to investigate the effectiveness of mitigation strategies that have been implemented to reduce AVCs. Hardy et al. (2006) investigated the effectiveness of seasonal animal movement advisory messages as a method of speed reduction tool with an ultimate goal of reducing AVCs. Glista et al. (2009) conducted a review study on existing wildlife road mortality mitigation strategies. Huijser et al. (2006) examined the prospect of an animal detection system to reduce AVCs. Evink (2002) undertook a synthesis study to determine how the state departments of transportation (DOTs) addressed the interaction between wildlife ecology and roadways.

The literature review above suggested that there was no scarcity of studies on AVCs. However, studies investigating trends and characteristics of AVCs at the national level were old, and for the state of Wyoming, has not been done yet. This warranted further study investigating trends and characteristics of AVCs considering the police-reported crash data for the entire state of Wyoming. 


\section{Data preparation}

Data used in this study were collected from WYDOT. All police-reported crashes from 2010 to 2019 were obtained in three excel files. The three files were related to crash level variables, involved level variables, and vehicle level variables. All the three files had a common variable called 'crashid', which was unique for each crash. AVCs were extracted from the file related to crash level variables. AVCs were considered as those crashes where the first harmful event was associated with an animal. The corresponding vehicle and involved level variables were then obtained by matching 'crashid'. For ten years' crash data, a total of 144,046 crashes were found. Of those 144,046 crashes, 27,034 were AVCs. The majority of AVCs were property damage only (PDO) crashes.

\section{Research methodology}

First, trend analysis was done for ten years: 2010-2019. AVCs were categorized based on severity. The crash data obtained from WYDOT divided the severity of AVCs into five levels: fatal, suspected serious injury, suspected minor injury, possible injury, and PDO crashes. The proportion of fatal, injury (suspected serious injury, suspected minor injury, possible injury), and PDO AVCs to that of total fatal, injury, and PDO crashes for each year were also computed. The data for vehicle miles traveled (VMT) for the last ten years were obtained from WYDOT's website (WYDOT, 2021). AVC rates per 100 million VMT were calculated for ten years. Types of animals involved in crashes were also examined. Then, the AVC rate per 100 million VMT for important driver, vehicular, roadway, and environmental conditions related factors were computed. Combined AVC data for ten years (2010-2019) as well as combined VMT data for the same time range were used for AVC rate analysis. Crash month, day of the week, time of day, light condition, and weather condition were considered as important environmental conditions related factors. Posted speed limit and road surface conditions were considered as roadway-related factors. Driver's factors that were considered were driver's age, gender, and usage of safety equipment. For vehicular factors, vehicle maneuver and estimated vehicle speed were considered. Vehicle type was not possible to examine because of missing data. Also, several other variables such as road surface type, road surface character, and whether drivers were under influence of alcohol were not possible to investigate because of missing information.

Next, it was the intention of the study to examine how different driver, vehicle, roadway, and environmental condition related factors affect the severity of AVCs. Logistic regression model was developed with the important driver, vehicle, roadway, and environmental condition related factors as explanatory variables. The dependent variable in this study was whether the AVC was fatal, suspected serious injury, suspected minor injury, or possible injury crash. The binary response variable was assigned the value of ' 1 ' if the AVC severity is fatal, suspected serious injury, suspected minor injury, or possible injury and '0' otherwise. AVCs for ten years (2010-2019) were used for the logistic regression model.

Since the dependent variable was binary, binary logistic regression model was identified as the best approach to identify the factors that influence the severity of AVCs. In the case of binary logit model, the response variable takes the form of either 0 or 1 . For $m$ explanatory variables and $i=1,2,3, \ldots ., n$ individuals, the model will take the form as follows (Allison, 1999):

$$
\log \left[\frac{\lambda_{i}}{1-\lambda_{i}}\right]=\alpha+\beta_{1} x_{i 1}+\beta_{2} x_{i 2}+\cdots . . \beta_{m} x_{i m}
$$

where $\lambda_{i}$ is the probability that $y_{i}=1$,

$\alpha=$ Intercept parameter,

$\beta=$ vector of slope parameters,

$x_{i}=$ vector of explanatory variables.

All of the analyses were conducted using statistical software 'SAS'. The maximum likelihood was estimated using the proc logistic procedure of the SAS software package (SAS Institute, 2015).

To check whether there is any collinearity between explanatory variables, a correlation matrix produced by proc corr in SAS was used. Once a variable was identified with correlation coefficient greater than 0.5, a linear regression model was used to further examine the variables (Dissanayake and Roy, 2014). Tolerance (TOL) and variance inflation factor (VIF) were generated by using proc reg in SAS software to check the correlation (SAS Institute, 2015). If the tolerance is low, it indicates that there 
exists multi-collinearity. For this study, variables that have tolerance values lower than 0.4 were removed from the model.

\section{Analysis of results}

\subsection{Trend analysis of crashes and crash rate}

To investigate the trends of AVCs, ten years' crash data from 2010-2019 were analyzed. As shown in Figure 1 (a), the percentage of AVCs to that of total crashes started to increase from the year 2014, with the highest being observed in 2016, and then it gradually started decreasing. The year 2013 stands out because of a relatively low percentage of total AVCs. All crashes, as well as all AVCs, were then categorized based on severity. Fatal injury, suspected serious injury, suspected minor injury, and possible injury crashes were combined and were referred to as fatal and injury crashes in the Figure. The percentage of fatal and injury AVCs to that of total fatal and injury crashes is shown in Figure 1 (a). The percentage ranged from around 5\% to 14\%, with the highest being observed in 2017 and the lowest in 2014. The percentage of PDO AVCs to that of total PDO crashes is also shown in the Figure. Since a significant portion of AVCs is PDO crashes, the percentage of PDO AVCs to that of total PDO crashes was higher than the percentage of total AVCs to that of total crashes.

To calculate the crash rate, VMT data were collected from the website of WYDOT. The trends of AVC rate per 100 million VMT are shown in Figure 1(b). As seen in Figure 1(b), the crash rate was found to have a similar trend as AVCs. The crash rate had an increasing trend from the year 2013 (35.48 per 100 million VMT) until 2016 (46.91 per 100 million VMT), and then it started to decrease.

Figure 1 (a): Percentage of the total, injury, and PDO animal-vehicle crashes to that of total crashes, total injury crashes, and total PDO crashes

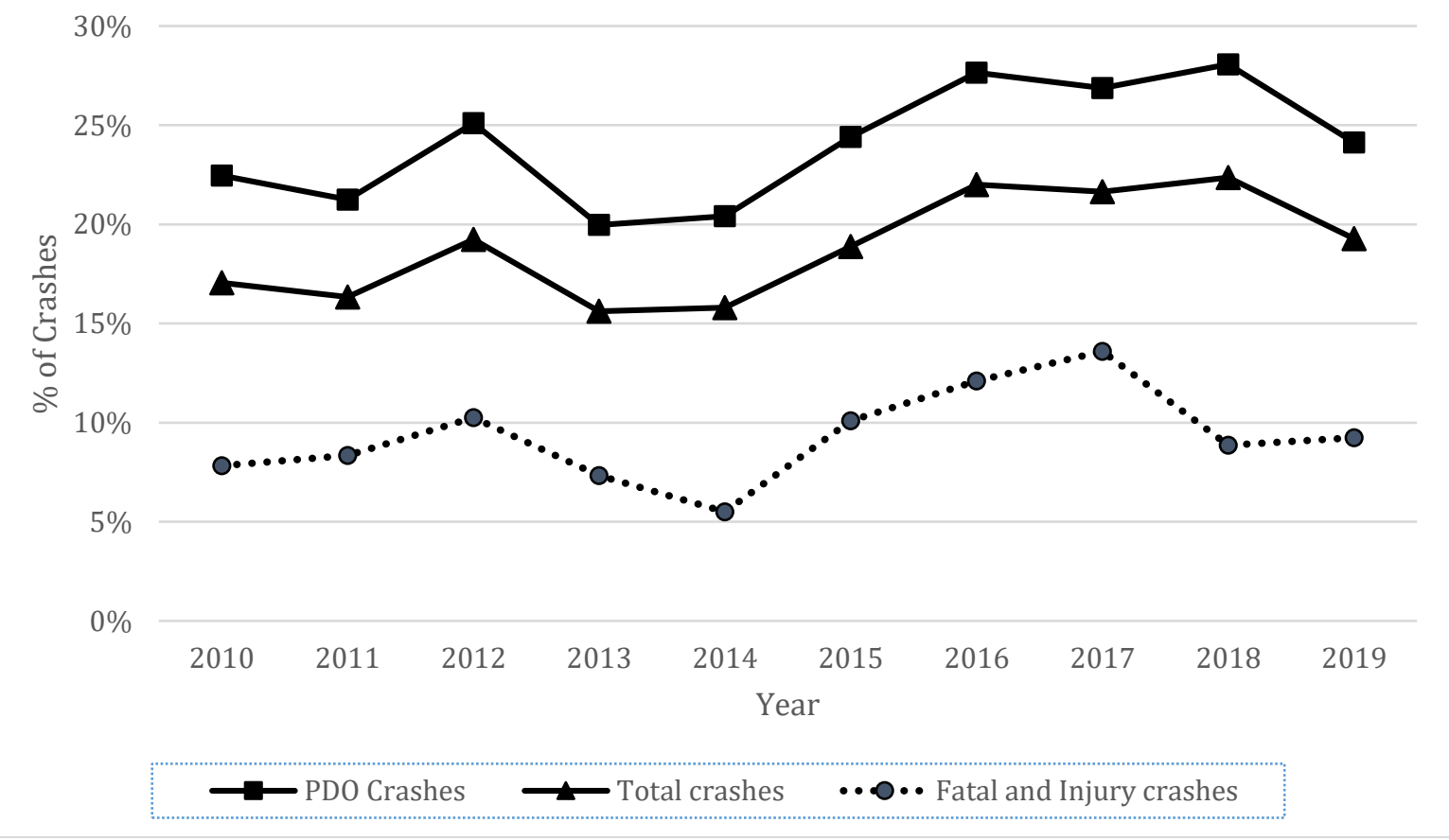


Figure 1 (b): Annual trend in AVCs per 100 million vehicle miles traveled

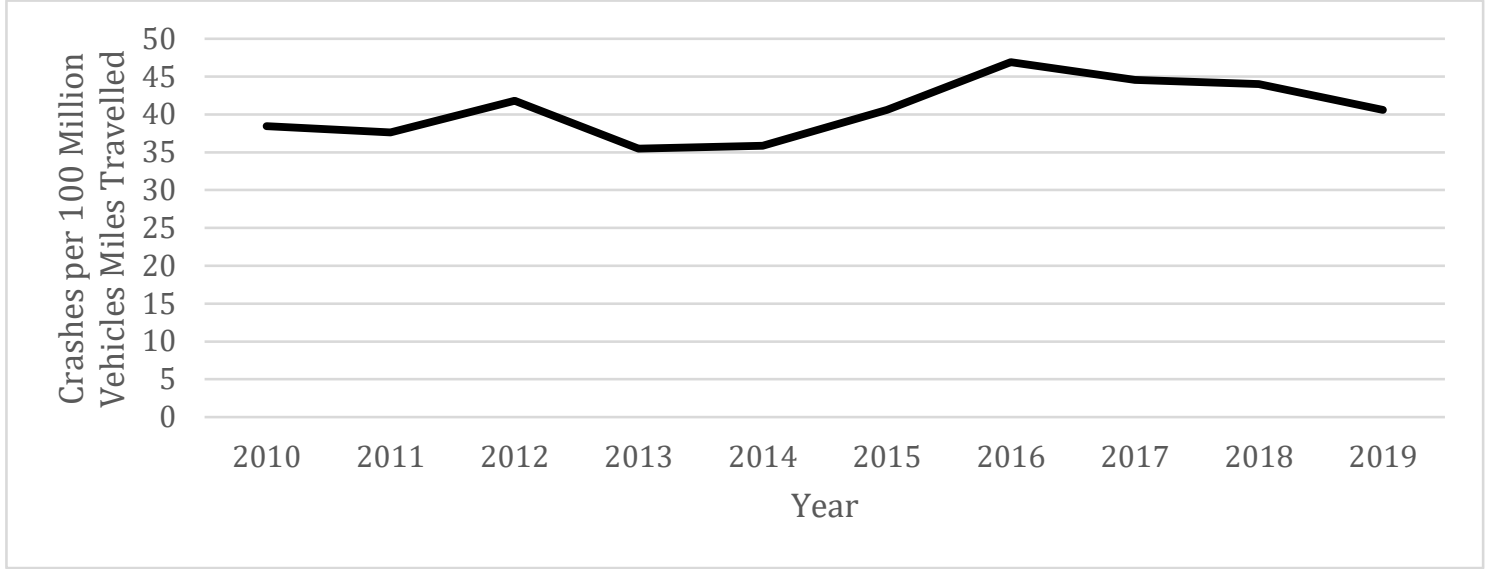

\subsection{Composition of animals, environmental condition, roadway, driver and vehicular factors related to AVCs}

\subsubsection{Type of animals}

When the type of animals involved in crashes was investigated, it was found that a vast majority of animals were deer (78.99\%). Antelope, cow, and elk were other notable animals that were also observed as seen in Figure 2. Buffalo, sheep, horse, pig, and dog were combined and were noted as "other domestic", the percentage of which was very small (2.29\%). There was also a very small percentage of other wild animals, which included moose.

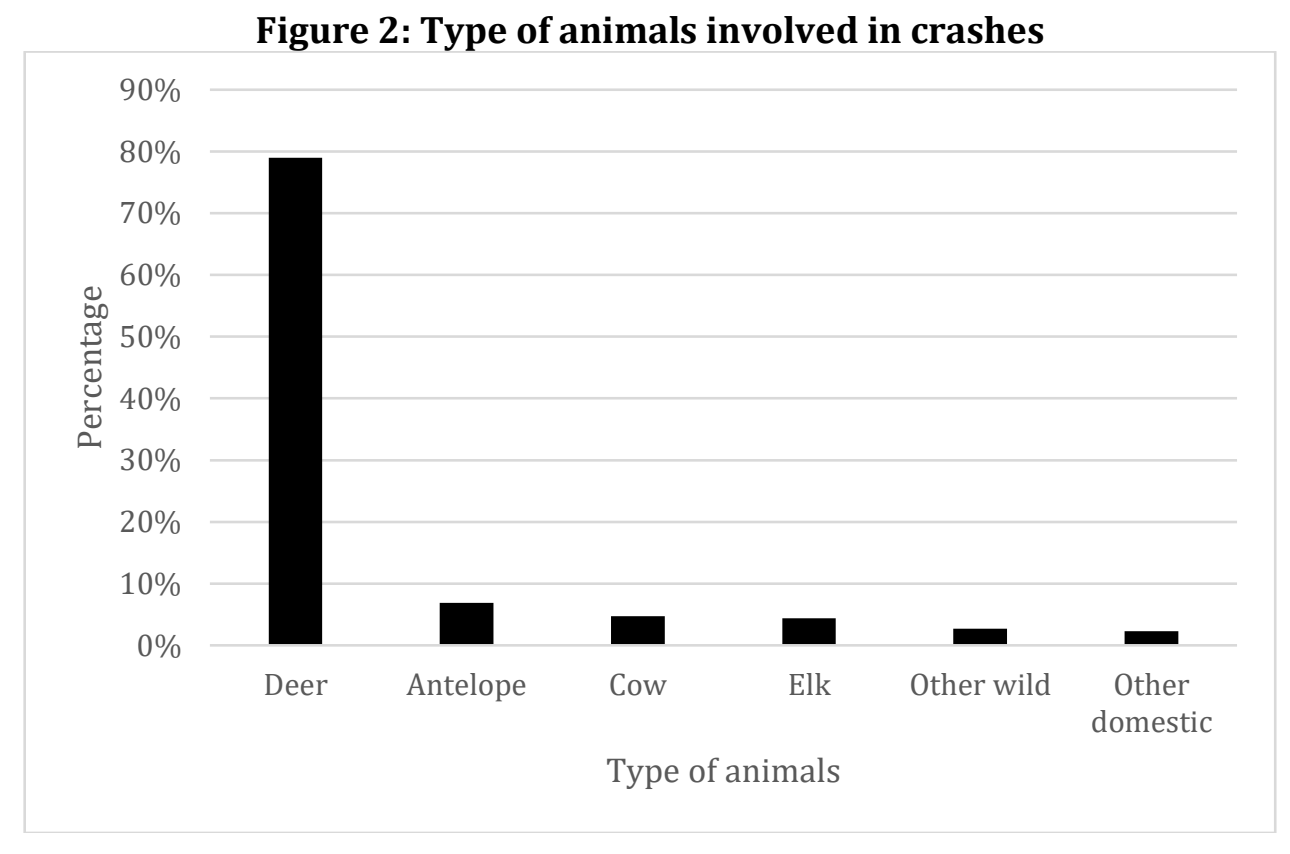

\subsubsection{Environmental conditions}

Temporal factors such as the month of the year, time of the day, and day of the week as well as light condition, and weather condition were considered as environmental conditions related factors. AVC rate per 100 million VMT was calculated by month, hour, day, light condition, and weather condition. The crash rate represents the number of AVCs that occurred in a selected month, hour, day, light condition, or weather condition divided by 100 million VMT.

AVC crash rate by month is shown in Figure 3 (a). It can be seen from the figure that the crash rate ranged between 1.5 crashes and 5.8 crashes per 100 million VMT. The months from January to May showed lower crash rates than the months from June to November. The crash rate was the highest in 
November, most likely because November is considered to be the mating season for the animals in Wyoming.

Figure 3 (a): Rate of animal-vehicle crashes in each month of the year (2010-2019)

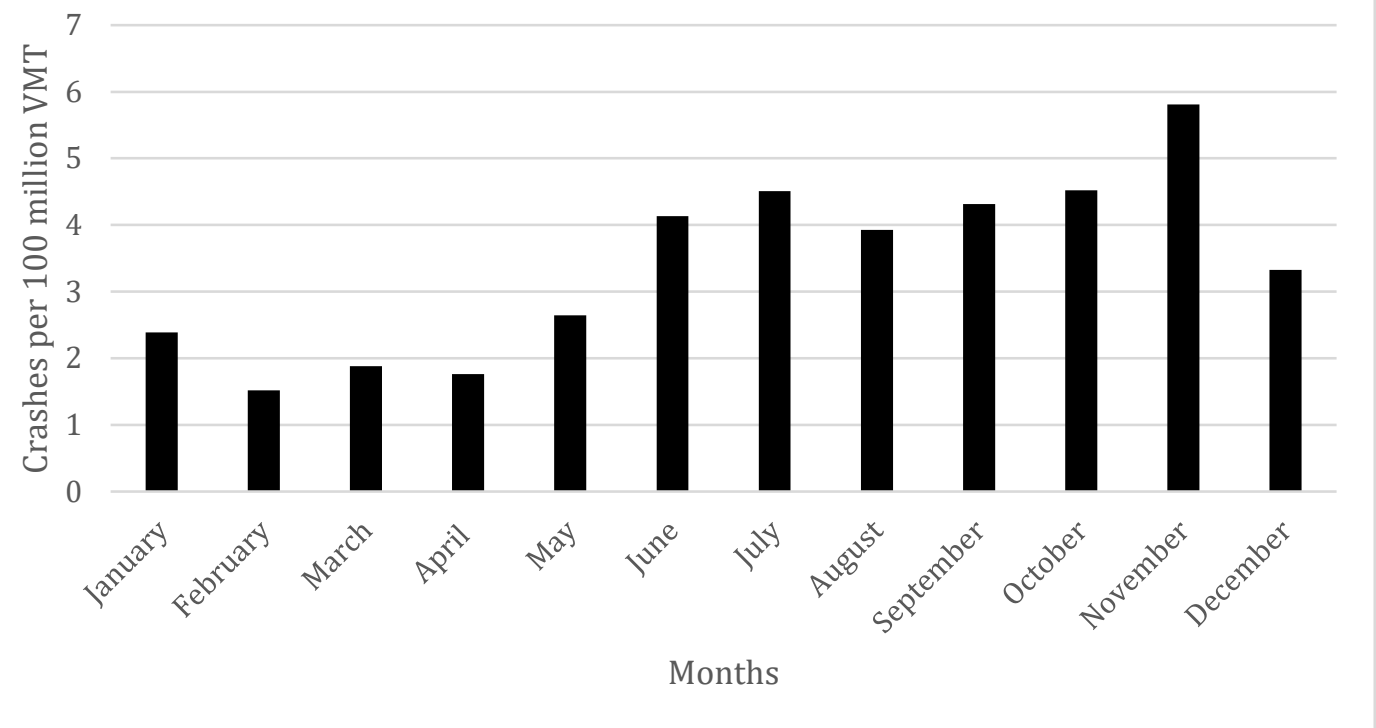

Figure 3 (b): Rate of animal-vehicle crashes occurring in each hour of the day

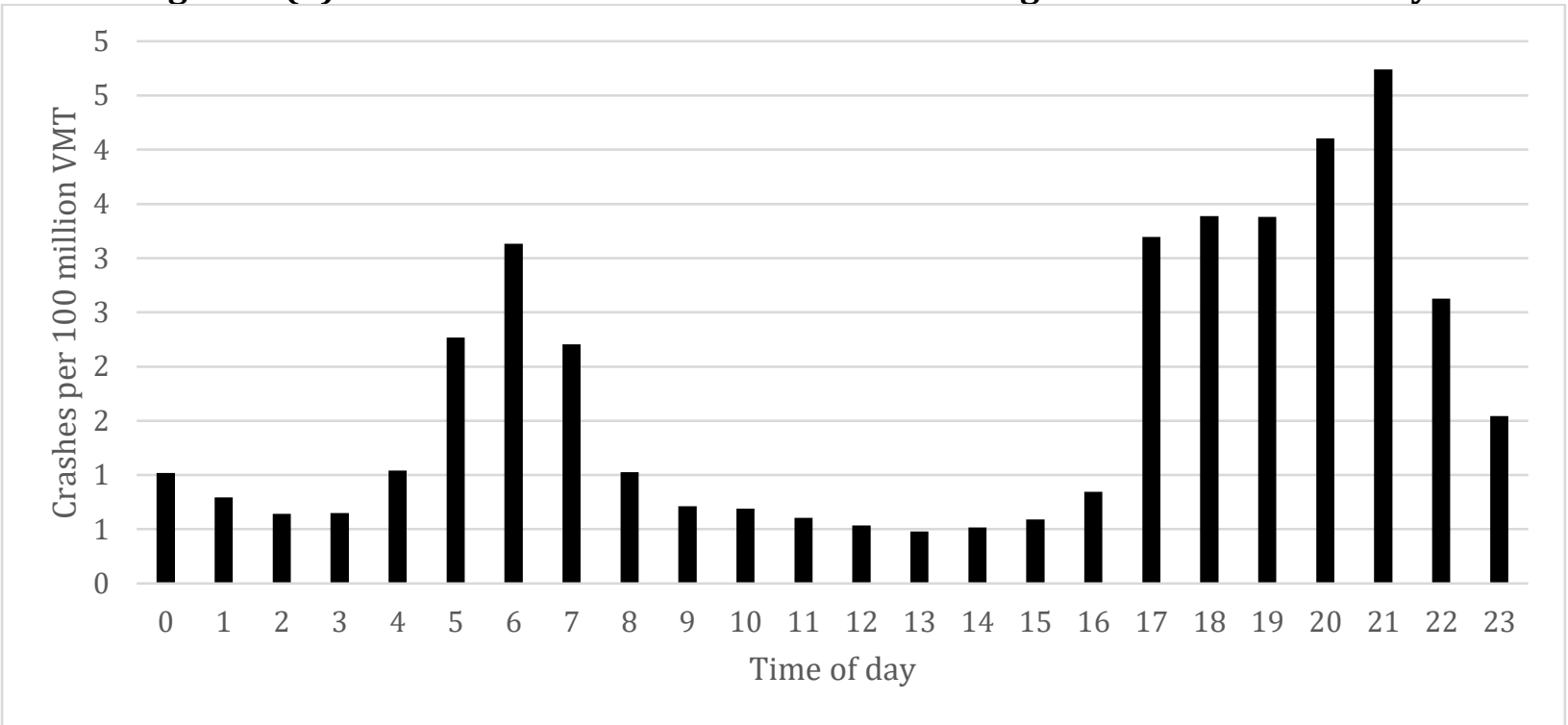

Hourly variation in AVC crash rate is shown in Figure 3 (b). As seen in the figure, there were two peaks in the AVC crash rates: dawn (between $5 \mathrm{am}$ and $7 \mathrm{am}$ ) and dusk (5 pm and $9 \mathrm{pm}$ ). The highest crash rate of AVCs can be observed between $8 \mathrm{pm}$ and $9 \mathrm{pm}$. Increased animal activity along with limited vision because of darkness could result in this trend. Almost similar finding was reported by previous studies (Chen and Wu, 2014; Sullivan, 2011; Khattak, 2003; Rowden et al., 2008).

When the day of the week was considered, it can be seen from Figure 3 (c) that the AVC rate was slightly higher on Friday. For the rest of the days, the AVC rate per 100 million VMT showed almost similar trends. 
Figure 3 (c): Rate of animal-vehicle crashes occurring on each day of the week

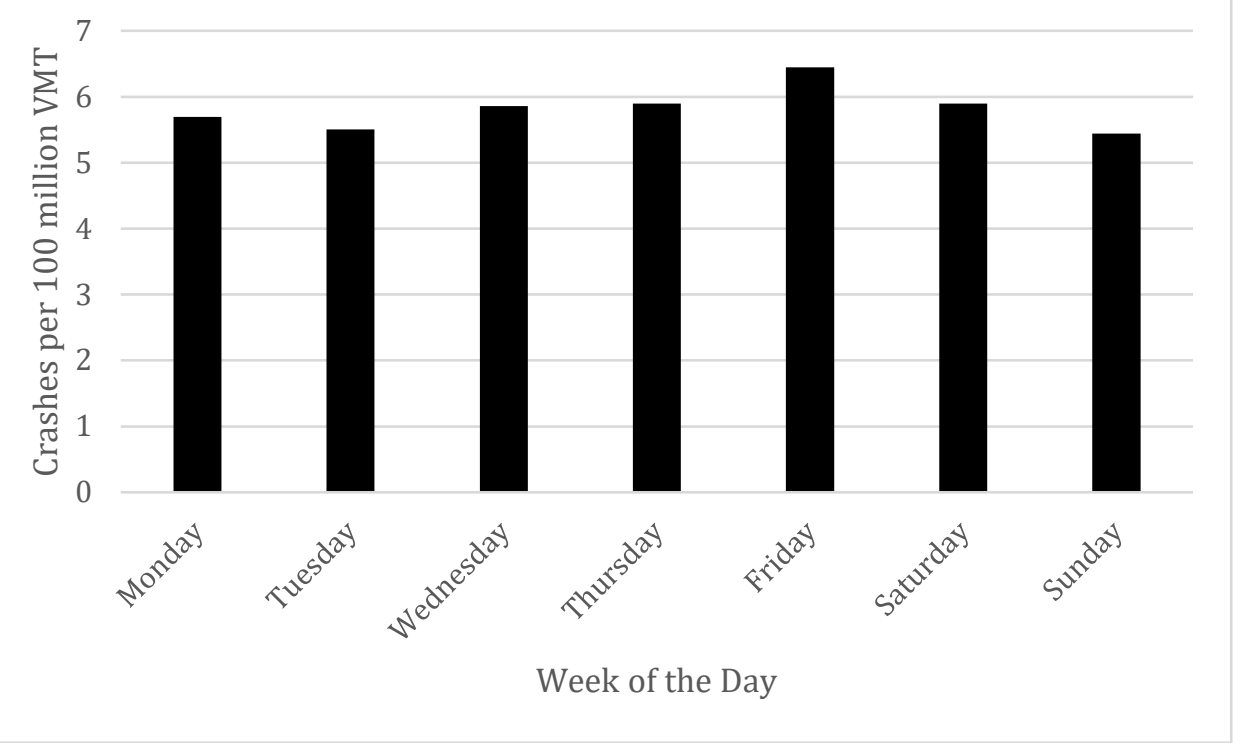

Figure 3 (d): Rate of animal-vehicle crashes occurring at different weather conditions

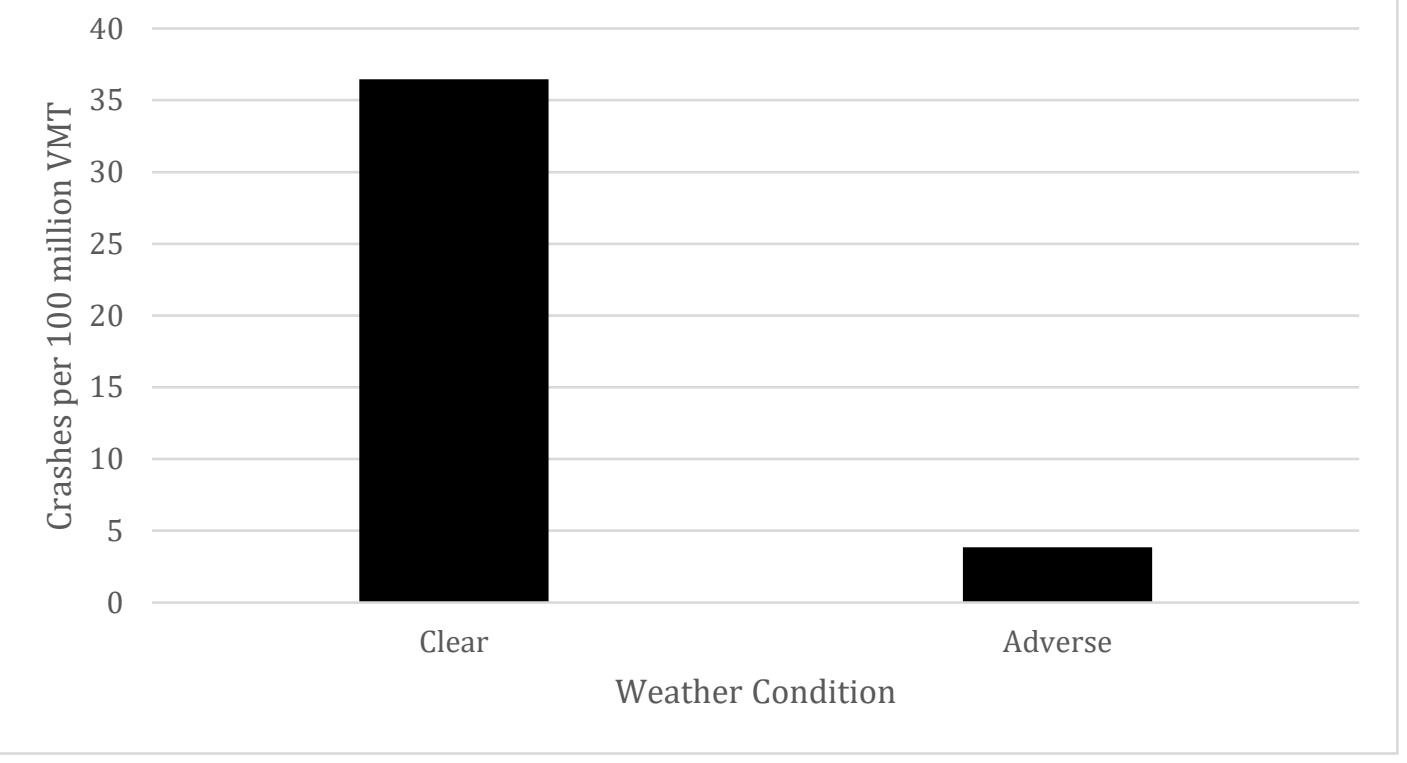

Weather condition was categorized as clear and adverse weather. Adverse weather was considered if there was rain, snow, blizzard, blowing snow, cloudy/overcast, severe wind, sleet/hail, blowing dust/sand/dirt, smoke, and fog. It can be seen from Figure 3 (d) that the AVC rate was more associated with clear weather. When the weather is adverse (e.g., snowing), drivers might reduce the speed, which lessens the chance of hitting animals.

When the AVC rate was calculated based on light condition, an interesting finding was observed, as shown in Figure 3 (e). A vast majority of AVCs occurred when it was dark and in unlit areas. Drivers are capable of seeing much farther down the roadway in daylight, and as such, can detect an obstacle and can perform an avoidance maneuver. During nighttime and especially when it is unlighted, drivers cannot see far ahead, so they can't detect and avoid the obstacle. The findings are well consistent with previous studies (Khattak, (2003); Sullivan, (2011); Chen and Wu, (2014); Morelle et al., (2013); Garrett and Conway, (1999)). 
Figure 3 (e): Rate of animal-vehicle crashes occurring at different light condition

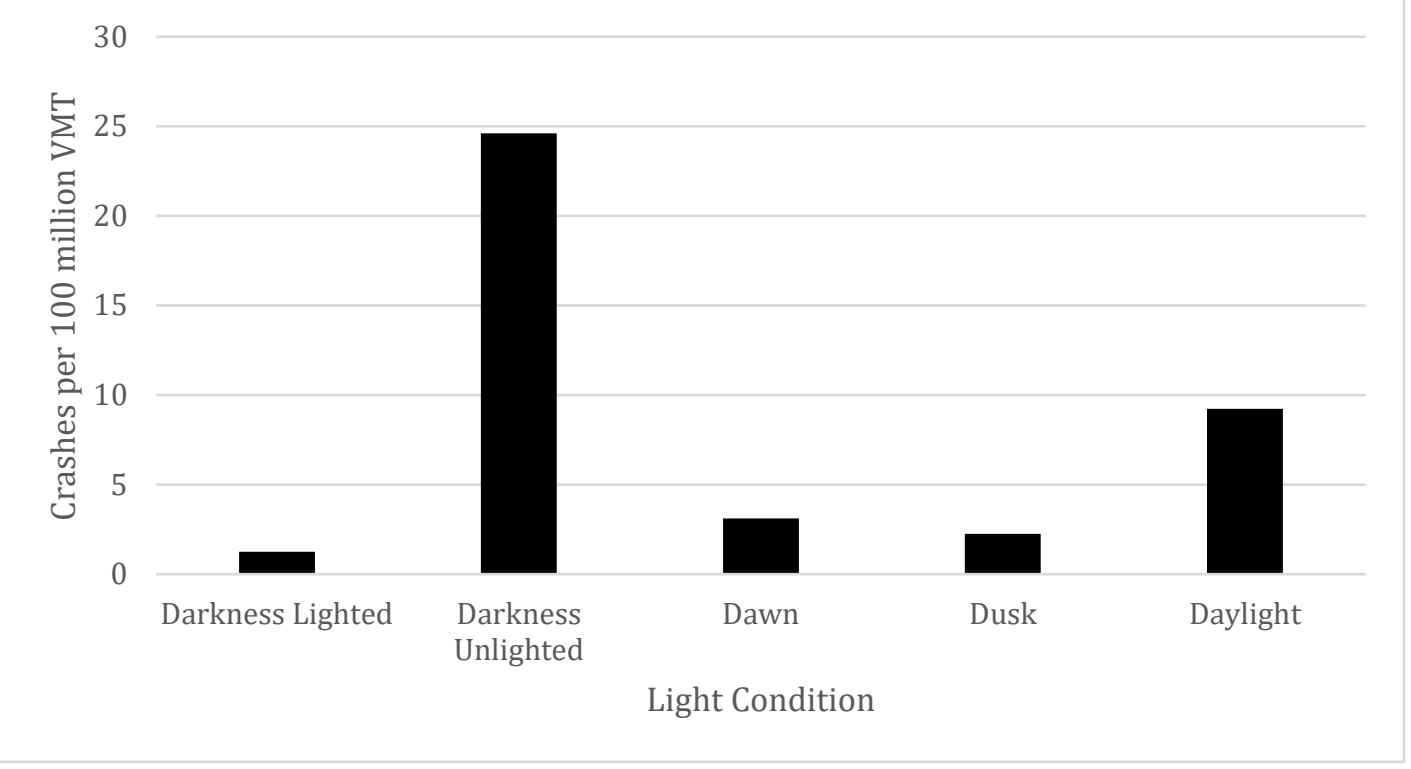

\subsubsection{Roadway variables}

Road surface condition and posted speed limit were the two factors that were considered as roadway variables. As mentioned before, several other roadway-related factors such as road surface type, road surface character could not be examined because of missing data. AVC rate was calculated by road surface condition and posted speed limit.

Figure 4 (a): Rate of animal-vehicle crashes based on road surface condition

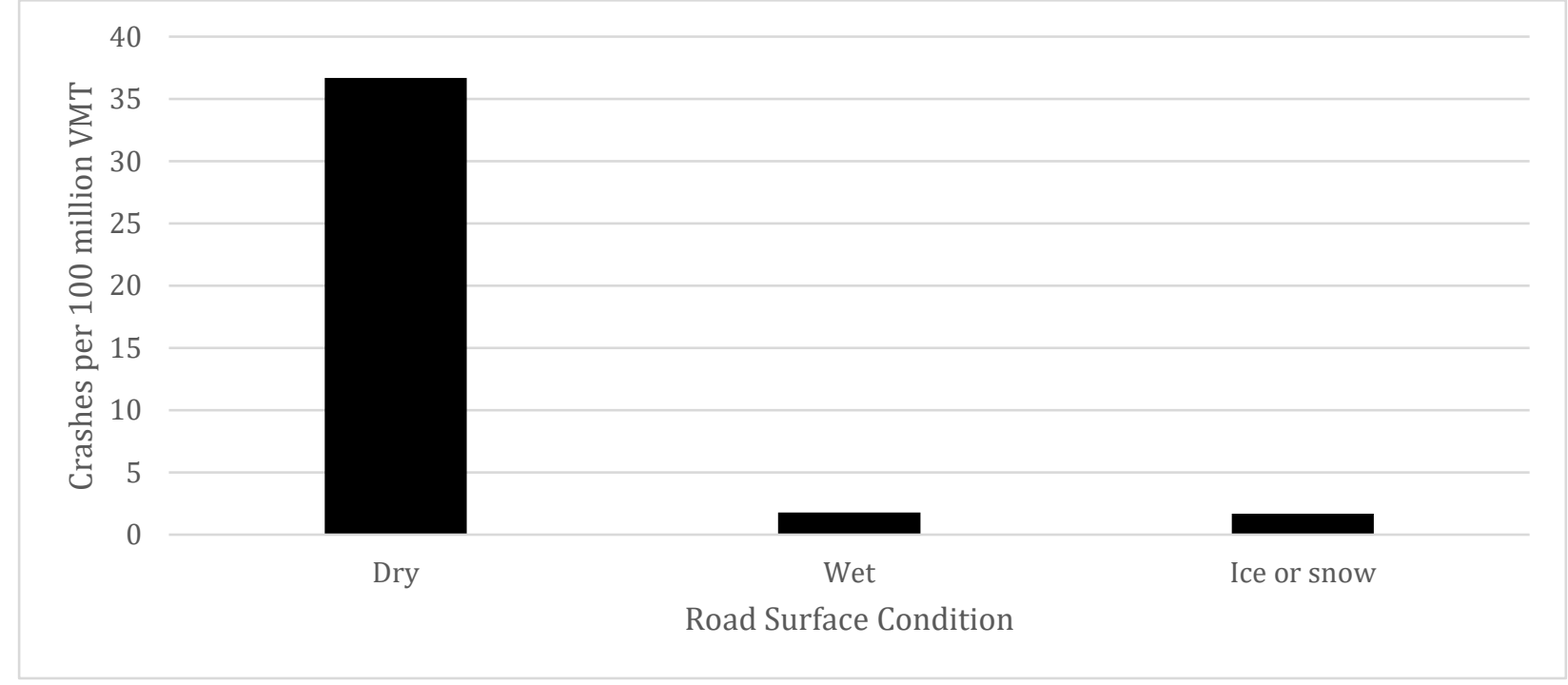


Figure 4 (b): Rate of animal-vehicle crashes based on posted speed limit

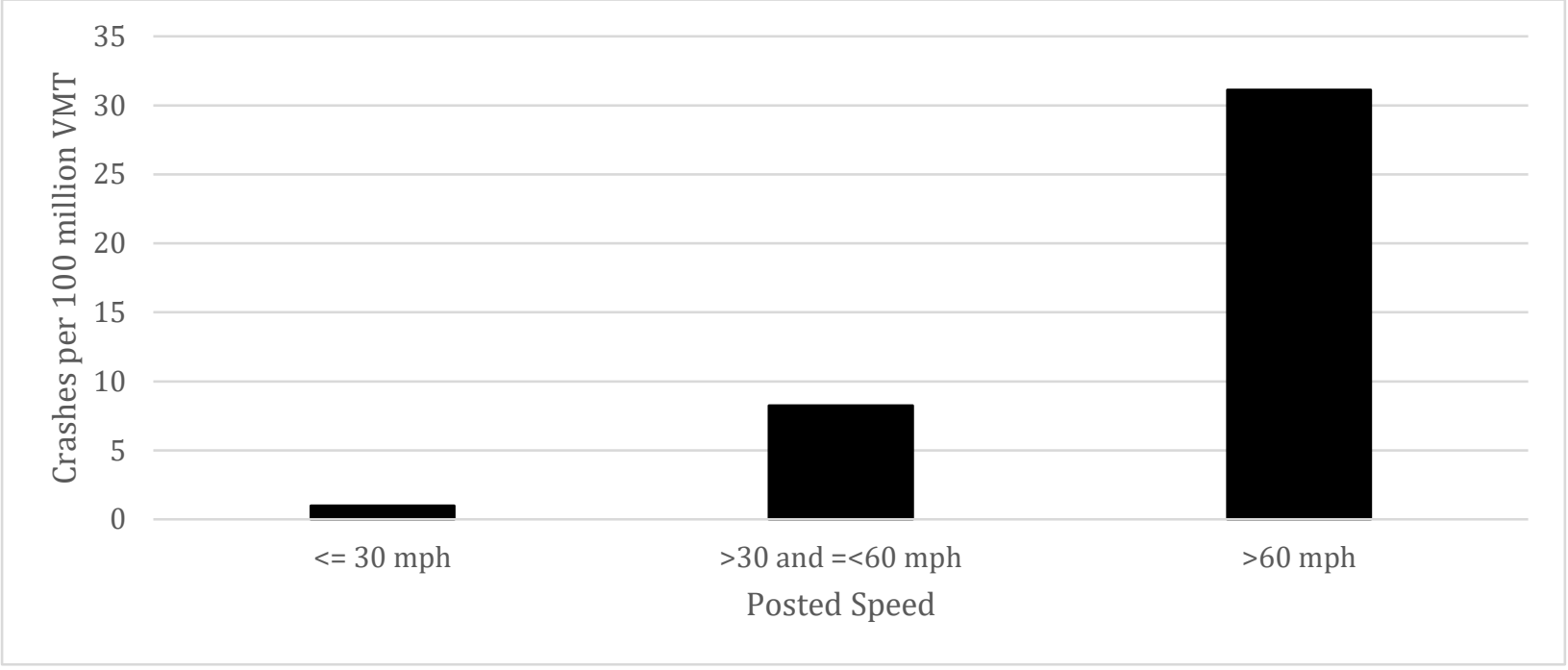

Three categories of road surface conditions were considered in this study: dry, wet, and ice/snow. It was found that a significant portion of AVC occurred in dry road surface conditions, as can be seen in Figure 4 (a). Probably, when the road surface is dry, drivers travel faster than usual, which lead to having more crashes on the dry road surface. This result was also obtained in a previous study by Marcoux, A. (2005).

The posted speed limit was categorized into three groups: less than or equal to $30 \mathrm{mph}$, greater than $30 \mathrm{mph}$ and less than or equal to $60 \mathrm{mph}$ and greater than $60 \mathrm{mph}$. As seen in Figure 4 (b), the crash rates tended to increase when posted speed limit increased. A significant portion of AVCs occurred when the speed limit was higher than $60 \mathrm{mph}$. This indicates that AVCs are more associated with higher speed. A similar result was also obtained in previous studies by Rowden et al. (2008); Sullivan (2011).

\subsubsection{Driver's factors}

Driver's gender, age, and whether restraint system was used or not were investigated as driver's factors. The AVC rate per 100 million VMT was calculated by driver's age, gender, usage of the restraint system.

Apart from male and female drivers involved in crashes, there was also a small portion of drivers whose gender was unknown. As seen in Figure 5 (a), more men than women drivers were involved in AVCs. The crash rate per 100 million VMT for male drivers was 26.1, whereas, for female drivers, it was 14.62. Male drivers were found more likely to be involved in AVCs in previous studies as well (Langley et al. (2006)). 
Figure 5 (a): Rate of animal-vehicle crashes based on driver's gender

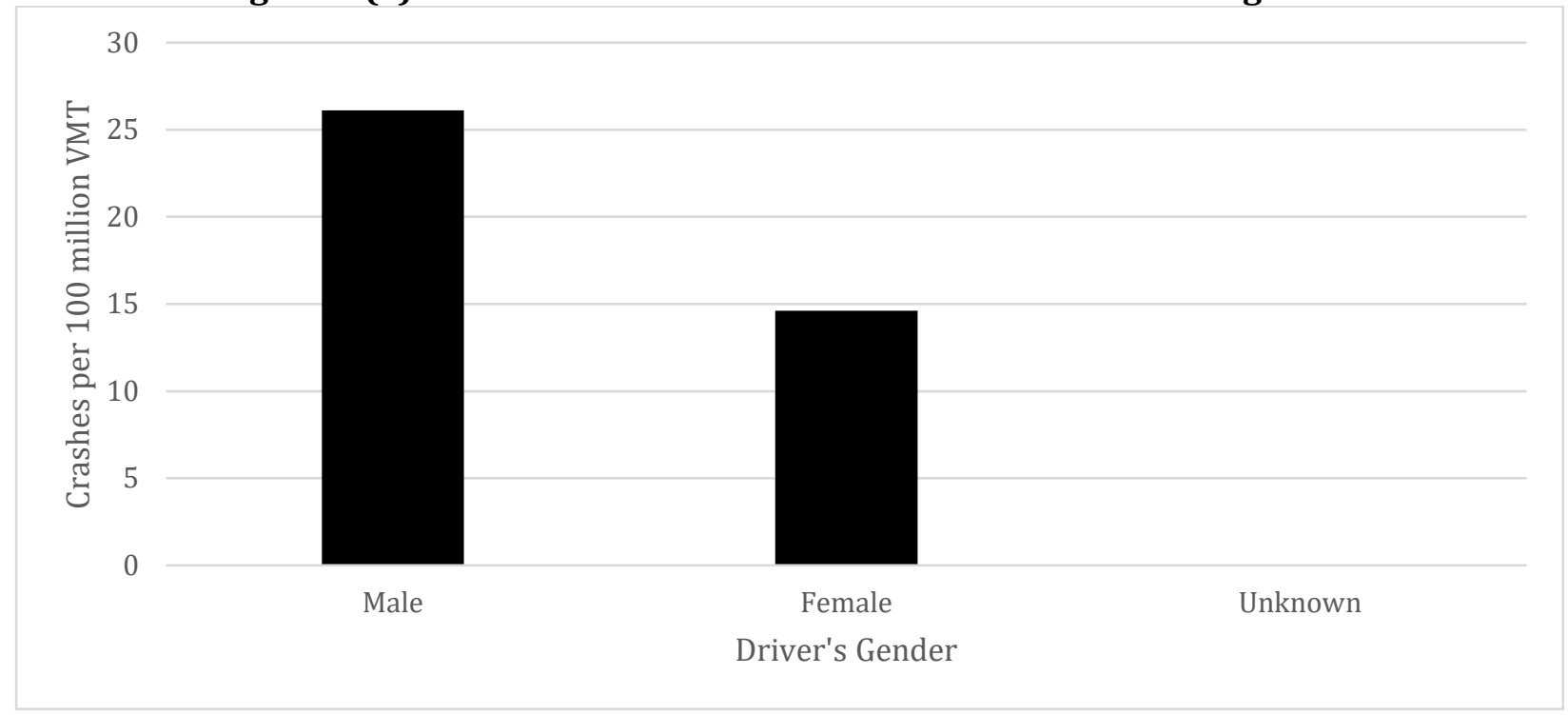

Figure 5 (b): Rate of animal-vehicle crashes based on driver's age

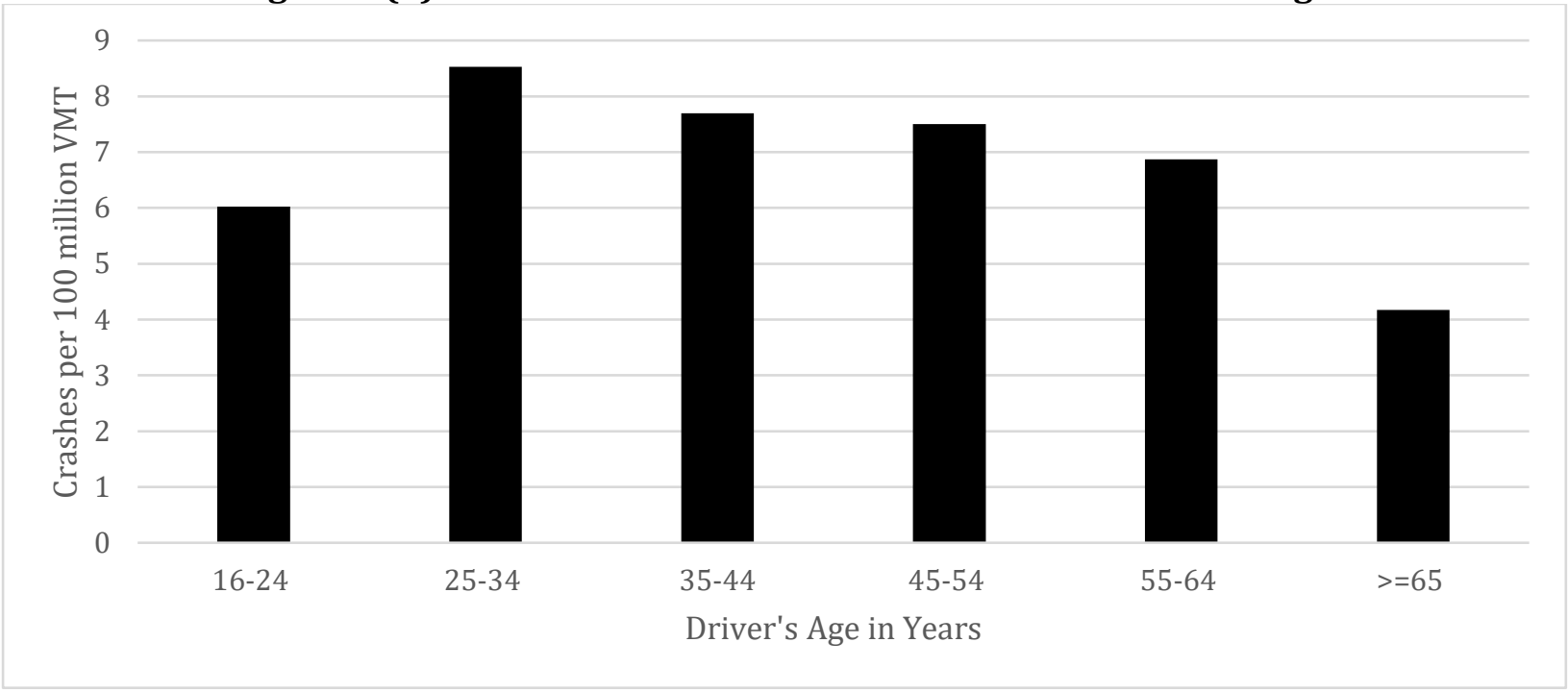

Driver's age was categorized into six groups. As seen in Figure 5 (b), the highest AVC rate was found for drivers aged between 25-34 years. The crash rate was found to decrease as the age of the drivers increased. This finding was probably because drivers aged between 25 and 34 years were less experienced than older drivers. However, the crash rate for younger drivers (aged between 16 and 24 years) was also found to be lower. 
Figure 5 (c): Rate of animal-vehicle crashes based on safety equipment

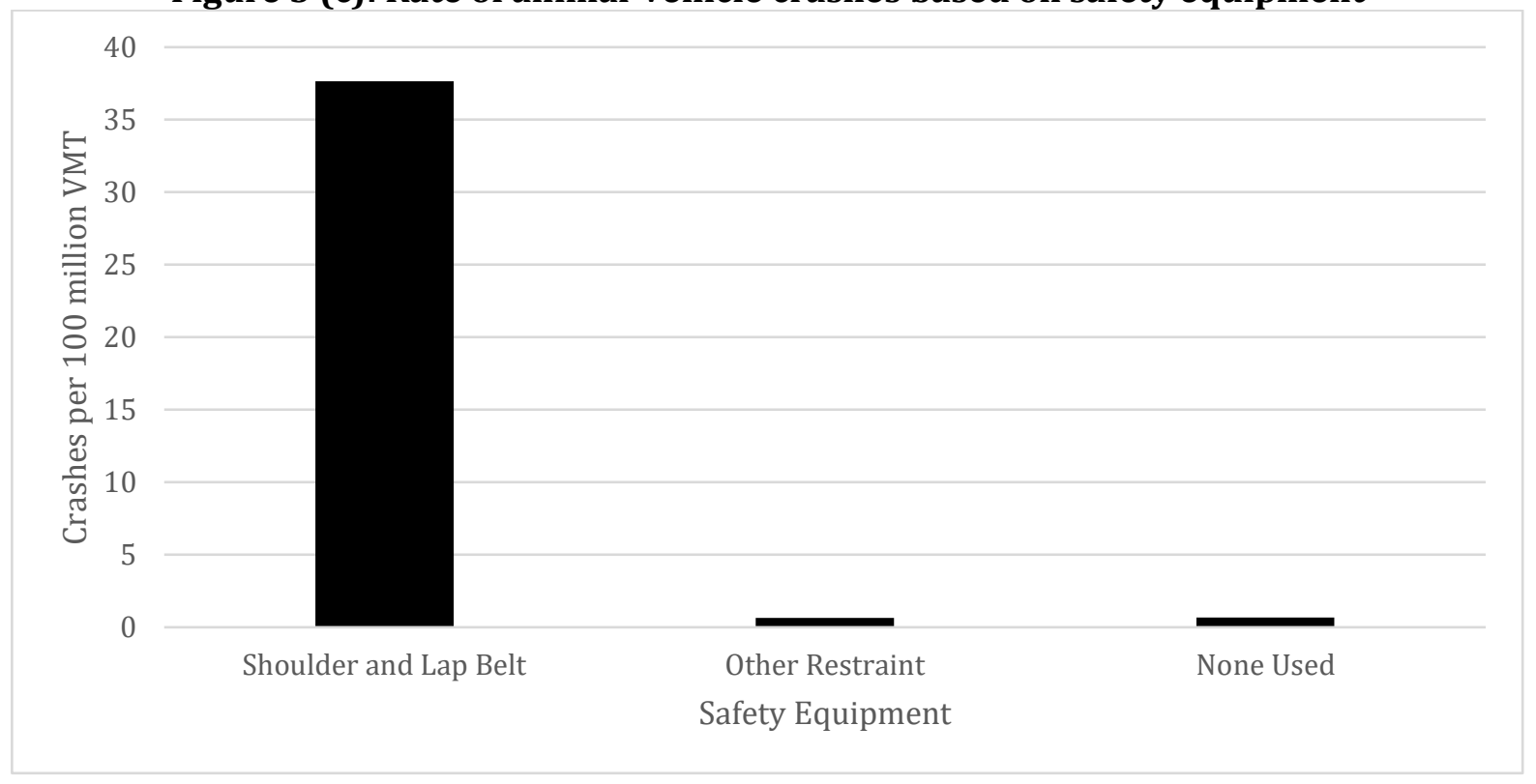

Whether drivers involved in AVCs used restraint systems or not was also investigated. The type of restraint system was categorized into two groups: shoulder and lap belt and others. Shoulder belt only, helmet, lap belt only, passive restraint, etc., were categorized as others. It can be seen from Figure 5 (c) that a significant number of drivers involved in AVCs used restraint systems. The crash rate when drivers used no restraint system was 0.67 per 100 million VMT. The findings were also found in previous studies done by Langley et al. (2006); Khattak (2003).

\subsubsection{Vehicular factors}

Vehicle maneuver and estimated vehicle speed during crashes were only two factors that were considered under this category. Because of missing data, vehicle type was not possible to examine.

When estimated vehicle speed was analyzed, it was found that AVCs tended to occur when the estimated vehicle speed was more than $60 \mathrm{mph}$. As seen in Figure 6 (a), the AVC rate was 22.36 per 100 million VMT when the drivers were driving at a speed higher than $60 \mathrm{mph}$. The lower the speed of the vehicle, the lower the chances of vehicles being involved in AVCs. When a vehicle travels at a higher speed, it requires a longer stopping distance. Therefore, reaction time for a faster vehicle is shorter when an animal is perceived. This finding is consistent with a previous study (Lao et al., (2011a)).

AVC rate based on vehicle maneuver is shown in Figure 6 (b). Vehicle maneuvers were categorized into four groups: straight ahead, negotiating a curve, vehicles turning left or right, and others. Backing, changing lanes, entering and leaving a traffic lane, passing, slowing, stopped in traffic, traffic way maintenance were grouped into other maneuvers. It was found that most of the crashes occurred when vehicles were using straight maneuvers. This explains that AVCs were more common when vehicles were maneuvering straight ahead. 
Figure 6 (a): Rate of animal-vehicle crashes based on estimated vehicle speed

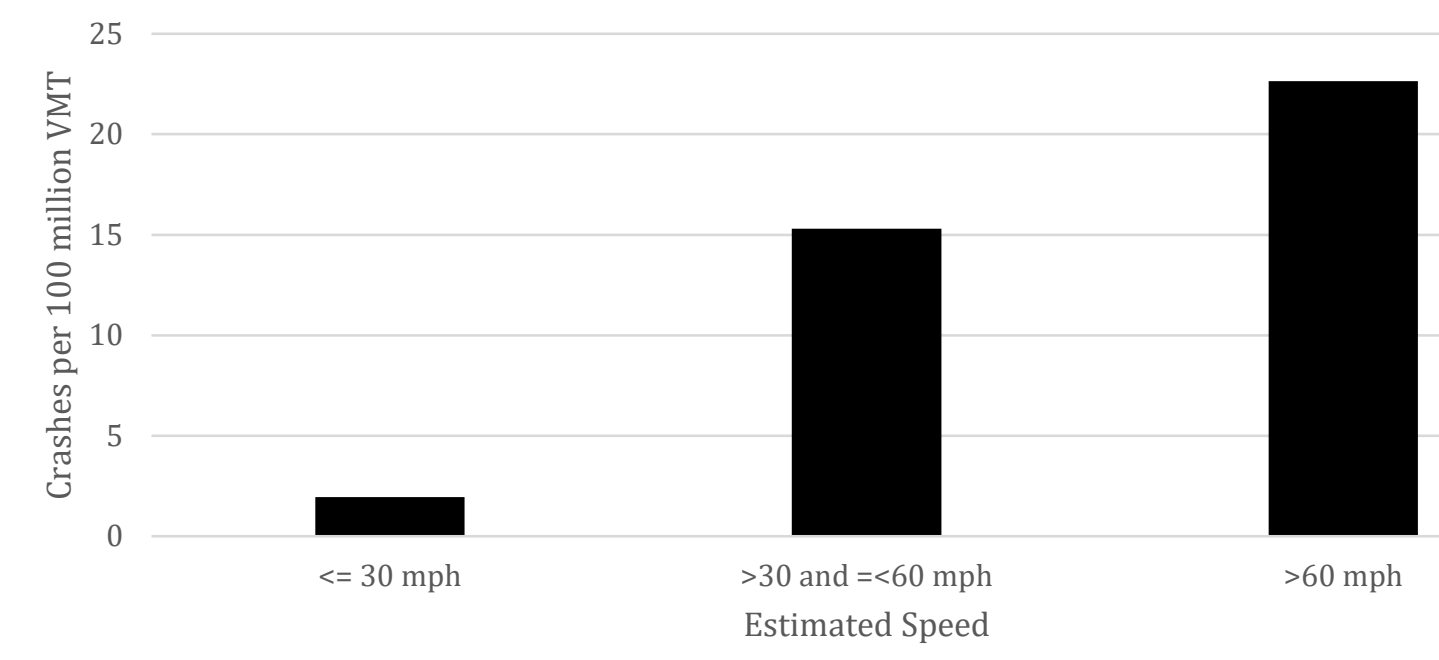

Figure 6 (b): Percentage of animal and non-animal crashes based on vehicle maneuver

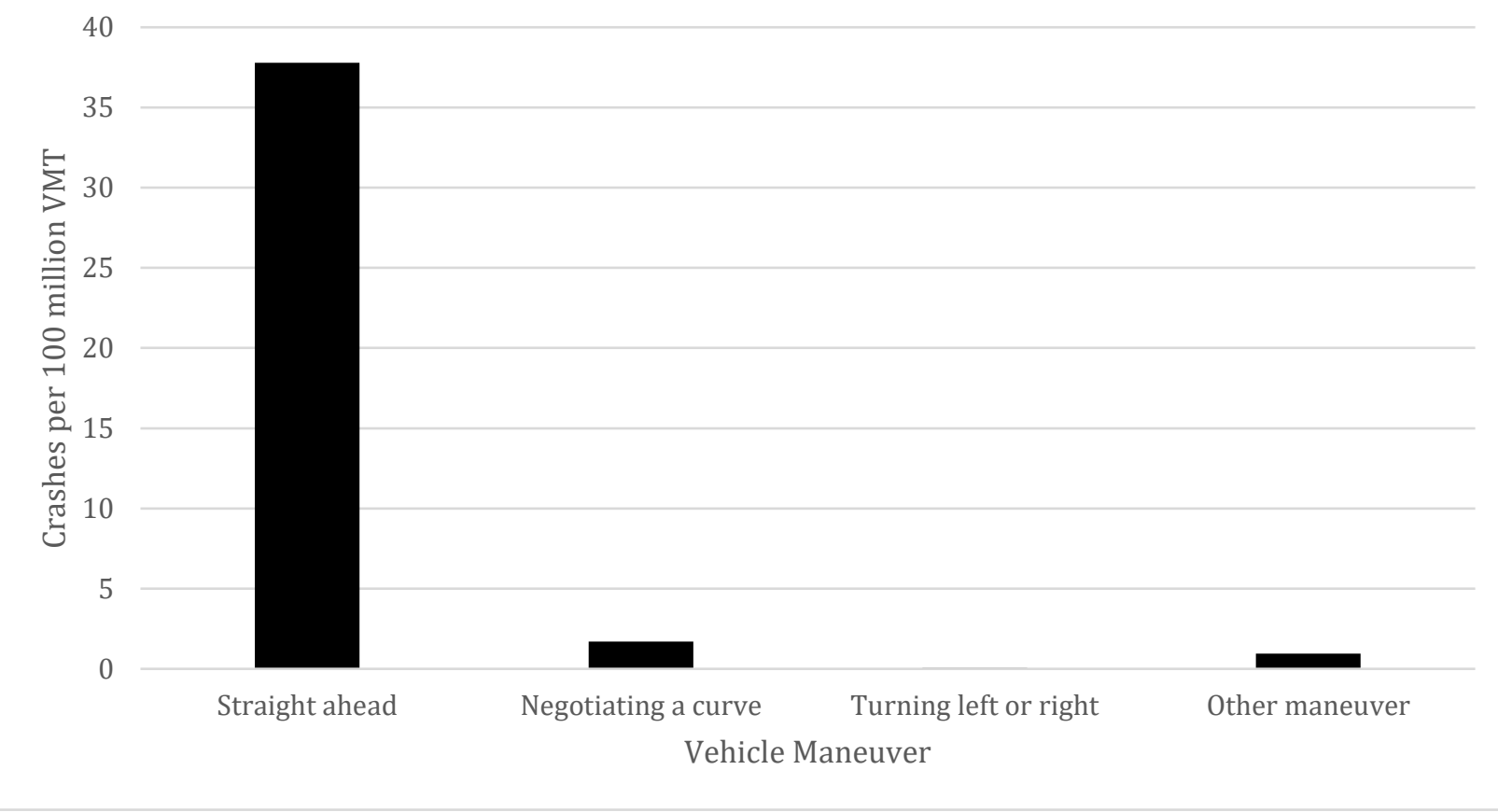

Table 1: Results of logistic regression model: 2010-2019

\begin{tabular}{|c|c|c|c|}
\hline Variables & Parameter Estimates & P-value & Odds Ratio \\
\hline Constant & -2.096 & \multicolumn{2}{|c|}{$<0.0001$} \\
\hline \multicolumn{4}{|c|}{ Environmental Factors } \\
\hline Dark (Light Conditions) & -0.199 & 0.018 & 0.819 \\
\hline Night Time ( $5 \mathrm{pm}$ to $11: 59 \mathrm{pm}$ ) & - & - & - \\
\hline Dawn (5 am to $7: 59 \mathrm{am}$ ) & -0.681 & $<0.0001$ & 0.506 \\
\hline Time of Year (June to November) & 0.328 & 0.0005 & 1.388 \\
\hline Weekend & - & - & - \\
\hline Normal Weather & - & - & - \\
\hline \multicolumn{4}{|c|}{ Roadway Variables } \\
\hline Posted Speed $>45 \mathrm{mph}$ & 0.575 & $<0.0001$ & 1.776 \\
\hline Dry Road Surface & 1.703 & $<0.0001$ & 5.488 \\
\hline \multicolumn{4}{|c|}{ Driver Factors } \\
\hline Male & - & - & - \\
\hline Younger Drivers (16-24 years) & 0.238 & 0.025 & 1.269 \\
\hline Older Drivers ( $>35$ years) & 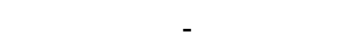 & - & - \\
\hline
\end{tabular}




\begin{tabular}{lccc}
\hline Restraint Used & & & $<0.0001$ \\
Airbag Not Deployed & -1.178 & $<0.0001$ & 0.308 \\
\hline Vehicular Factors & -2.148 & & 0.117 \\
\hline Initial Impact Head-on & & - & - \\
Straight Maneuver & - & 0.0007 & 0.648 \\
Estimated Travel Speed $>45 \mathrm{mph}$ & -0.433 & - & - \\
\hline & - & & Intercept and Covariates \\
\hline Criterion & Model Fit Statistics & 5548.341 \\
\hline AIC & Intercept only & 5630.390 \\
SC & 6542.472 & 5528.341 \\
-2 Log L & 6550.677 & & \\
\hline
\end{tabular}

-: Statistically insignificant parameter removed

\subsection{Results of logistic regression model}

Logistic regression model was developed to check how important driver, vehicle, roadway, and environmental condition related factors influence AVC severity. Binary logit model was developed, and explanatory variables significant at the 95\% confidence level were included in the final model. The response variable was whether the AVC severity is fatal injury, suspected serious injury, suspected minor injury, possible injury or not (Binary response $=1$ if the observation is a fatal, suspected serious injury, suspected minor injury or possible injury crash, $=0$ otherwise i.e., no injury or PDO crash). Initially, all the variables were included in the model, and backward elimination procedure was attempted to eliminate statistically insignificant parameters. The result of the logistic regression model was listed in Table1 and was described in the following content.

Among different environmental condition related factors being considered, it was found that dark light condition (when it is dark and unlit) reduces the severity of AVCs. This is perhaps because when it is dark and unlit, drivers take extra caution while driving. Dawn time (5 am to 7:59 am) as well was found to reduce AVC severity. When AVCs took place between June and November, it was found that it increased the severity of AVCs. The odds ratio of 1.388 for the time of year suggests that the odds of AVCs, which took place between June and November, had 1.388 times the chance of being severe than AVCs took place in other months of the year. This finding is well consistent with a previous study by Savolainen and Ghosh (2008). Weekend and normal weather were found statistically insignificant at 95\% confidence level, meaning they did not influence AVC severity.

When different roadway variables were considered, it was found that AVCs were more likely to be severe when the posted speed limit was higher than $45 \mathrm{mph}$. The odds ratio of 1.776 suggested that the probability of AVCs tended to be 1.776 times severe when the posted speed limit was higher than $45 \mathrm{mph}$. Similar findings were also found in previous studies (Savolainen and Ghosh (2008); Al-Bdairi et al., (2020)). Dry road surface also tended to increase the severity of AVCs. The odds of AVC being severe was 5.488 times higher when the road surface was dry.

When driver factors were considered, it can be seen from Table 1 that male and older drivers did not influence the severity of AVCs. However, drivers who were younger (16-24 years) were more likely to be involved in severe AVCs. When restraint system was used by drivers, they tended to reduce the severity of AVCs. Also, AVC severity tended to be less severe when the airbag was not deployed. Driver's age and usage of restraint system were also analyzed by other researchers (Savolainen and Ghosh (2008)), and similar results were obtained.

Finally, vehicular factors such as initial impact, vehicle maneuver, and estimated travel speed of vehicles were examined. The result showed that AVCs tended to be less severe when vehicles were using straight maneuvers. Lastly, when the estimated travel speed of vehicle was considered (estimated speed $>45 \mathrm{mph}$ ), it was found that it did not influence AVC severity.

\section{Conclusions}

This study investigated trends and characteristics of AVCs using police-reported crash data for ten years (2010-2019) collected from WYDOT. The percentage of fatal and injury, PDO and total AVCs to that of all fatal and injury, all PDO and all crashes were investigated respectively for ten years. Then, the crash rate of AVCs per million VMT was analyzed. Important driver, vehicle, roadway, and 
environmental condition related factors were examined. Finally, logistic regression model was developed to find out how different factors influence the severity of AVCs. Important findings from the study are summarized in the following content.

Trend analysis of AVCs revealed that AVCs ranged from around $15 \%$ to $22 \%$ of total crashes in Wyoming. For ten years' crash data, it was found that there were a total of 27,034 AVCs took place in Wyoming. Among those 27,034 crashes, 97.11\% were PDO crashes. Fatal and all other injury AVCs ranged from $5.5 \%$ (in 2014) to 13.60\% (in 2017) of total fatal and injury crashes. The crash rate per VMT was calculated, and the trends of crash rate were found to have similar trends as AVCs. When the type of animals involved in crashes was analyzed, it was found that $78.99 \%$ of the total animals were deer. The most important characteristics of AVCs were related to environmental conditions. Temporal characteristics such as time of day, the month of the year, and day of the week, as well as light condition, and weather condition were analyzed as environmental condition related factors. AVCs were found to have two peaks: dawn and night time. AVCs were also more prominent when it was dark and unlighted and when there was no adverse weather condition. It was also found that the rate of AVCs is the highest for November. The AVC rate tended to increase with an increase in posted speed limit and with an increase in estimated speed of vehicle.

Finally, logistic regression model was developed to see how various factors which were found dominant in AVCs affect the severity of AVCs. The result of the logistic regression model showed that dark light condition and dawn time tended to decrease AVC severity. AVCs that took place between June and November tended to be severe. Also, the odds of AVCs being severe was 1.776 times higher when the posted speed limit was greater than $45 \mathrm{mph}$. Younger drivers were also found to increase the severity of AVCs. When drivers used some sort of restraint system, it tended to decrease the crash severity. AVCs were also found to be less severe when vehicles had straight maneuvers.

Various factors which were found prevalent in AVCs could help DOTs and other agencies to take effective measures by identifying this as a high-priority focus area. Based on the results found in this study, effective countermeasures can be suggested which will reduce the number of AVCs. Countermeasures such as speed limit reductions during night time (Huijser et al., 2006), warning signs for drivers so that drivers can be aware of the approaching animal (Hardy et al., 2006), various physical control measures, which include construction of overpasses and underpasses, fencing, at-grade crossings, etc. (McCollister and Van Manen (2010); Evink (2002); Glista et al. (2009)) could be effective. Driver education and awareness program could also be a viable option to reduce the AVCs.

Unfortunately, the crash data collected from WYDOT have limitations. It does not provide information about the type of vehicles involved in AVCs, nor does it have information about the race and ethnicity of drivers. The influence of alcohol is also an important variable, but this variable was not possible to examine since it was unknown whether the drivers were under the influence of alcohol for the majority of AVCs. Also, road surface type and road surface character were not reported for a significant number of AVCs and hence were not possible to compare. And lastly, since a majority of AVCs are PDO crashes, there are chances that AVCs will be unreported if the resulting damage is minor.

\section{Funding}

Not applicable

\section{Conflicts of interest/Competing interests}

Not applicable

\section{Acknowledgements}

The authors thank the anonymous reviewers for their suggestions. 


\section{Citation information}

Roy, U., \& Ksaibati, K. (2021). Investigating trends and characteristics of animal-vehicle crashes in Wyoming. Journal of Sustainable Development of Transport and Logistics, 6(2), 25-42. doi:10.14254/jsdtl.2021.6-2.2.

\section{References}

Al-Bdairi, N.S.S., Behnood, A., \& Hernandez, S. (2020). Temporal stability of driver injury severities in animal-vehicle collisions: A random parameters with heterogeneity in means (and variances) approach. Analytic Methods in Accident Research, 26. https://doi.org/10.1016/j.amar.2020.100120.

Allison, P. D. 1999. Logistic regression using the SAS System: Theory and application. SAS Institute Inc., SAS Campus Drive, Cary.

Bartonička, T., Andrášik, R., Dul'a, M., Sedoník, J., \& Bíl, M. (2018). Identification of local factors causing clustering of animal-vehicle collisions. The Journal of Wildlife Management, 82(5), 940-947. https://doi.org/10.1002/jwmg.21467.

Becker, S., Kauffman, M. \& Hubert, W. (2008). Spatial and temporal characteristics of moose highway crossings in the Buffalo Fork Valley, Wyoming. Report No. FHWA-WY-08/03F. Wyoming Department of Transportation.

Bíl, M., Andrášik, R., Svoboda, T., \& Sedoník, J. (2016). The KDE+ software: A tool for effective identification and ranking of animal-vehicle collision hotspots along networks. Landscape ecology, 31(2), 231-237.

Bíl, M., Andrášik, R., Dul'a, M., \& Sedoník, J. (2019). On reliable identification of factors influencing wildlife-vehicle collisions along roads.Journal of environmental management, 237, 297-304. https://doi.org/10.1016/j.jenvman.2019.02.076.

Chen, X., \& Wu, S. (2014). Examining patterns of animal-vehicle collisions in Alabama, USA. HumanWildlife Interactions, 8(2), 9. https://doi.org/10.26077/p18k-1089.

Cserkesz, T., \& Farkas, J. (2015). Annual trends in the number of wildlife-vehicle collisions on the main linear transport corridors (highway and railway) of Hungary. North-Western Journal of Zoology, 11(1), 41-50. http://biozoojournals.ro/nwjz/index.html.

Creech, T., Fairbank, E., Clevenger, A., Callahan, A., \& Ament, R. (2019). Differences in spatiotemporal patterns of vehicle collisions with wildlife and livestock. Environmental management, 64(6), 736745 .

Dai, Q., Young, R., \& Giessen, S. (2009). Evaluation of an active wildlife-sensing and driver warning system at Trapper's Point. Report No. FHWA-WY-09/03F. Wyoming Department of Transportation.

Danks, Z., \& Porter, W. (2010). Temporal, spatial, and landscape habitat characteristics of moosevehicle collisions in Western Maine. The Journal of Wildlife Management, 74(6), 1229-1241. https://doi.org/10.1111/j.1937-2817.2010.tb01243

Dissanayake, S., \& Roy, U. (2014). Crash severity analysis of single vehicle run-off-road crashes. Journal of Transportation Technologies, 4(1). https://doi.org/10.4236/jtts.2014.41001.

Eloff, P., \& Van Niekerk, A. (2008). Temporal patterns of animal-related traffic accidents in the Eastern Cape, South Africa. African Journal of Wildlife Research, 38(2), 153-162. https://doi.org/10.3957/0379-4369-38.2.153.

Evink, G. (2002). NCHRP 305. Interaction between Roadways and Wildlife Ecology: A Synthesis of Highway Practice. Transportation Research Board, National Academies of Sciences Engineering, and Medicine, Washington D.C.

Garrett, L.C., \& Conway, G.A. (1999). Characteristics of moose-vehicle collisions in Anchorage, Alaska, 1991-1995. Journal of Safety Research,30(4), 219-223. https://doi.org/10.1016/S00224375(99)00017-1.

Gkritza, K., Baird, M., \& Hans, Z.N. (2010). Deer-vehicle collisions, deer density, and land use in Iowa's urban deer herd management zones. Accident Analysis \& Prevention, 42(6), 1916-1925. https://doi.org/10.1016/j.aap.2010.05.013 
Glista, D.J., DeVault, T., \& DeWoody, J. (2009). A review of mitigation measures for reducing wildlife mortality on roadways. Landscape and Urban Planning, 91(1). https://doi.org/10.1016/j.landurbplan.2008.11.001.

Gordon, K., Anderson, S., Gribble, B., \& Johnson, M. (2001). Evaluation of the FLASH (Flashing Light Animal Sensing Host) System in Nugget Canyon, Wyoming. Report No. FHWA-WY-01/03F. Wyoming Department of Transportation.

Gunson, K.E., Chruszcz, B., \& Clevenger, A.P. (2003). Large animal-vehicle collisions in the Central Canadian Rocky Mountains: patterns and characteristics. In Proceedings of the 2003 International Conference on Ecology and Transportation. Center for Transportation and the Environment, North Carolina State University, Raleigh, NC, pp. 355-366.

Hardy, A., Lee, S., \& Al-Kaisy, A.F. (2006). Effectiveness of animal advisory messages on dynamic message signs as a speed reduction tool: Case study in rural Montana. Transportation Research Record, 1973(1). https://doi.org/10.1177/0361198106197300108.

Huijser, M., McGowen, P., Fuller, J., Hardy, A., Kociolek, A., Clevenger, A., Smith, D., \& Ament, R. (2008). Wildlife-Vehicle Collision Reduction Study: Report to Congress. Report Number FHWA-HRT-08-034. Federal Highway Administration, McLean, Virginia.

Huijser, M.P., McGowen, P.T., \& Camel, W. (2006). Animal vehicle crash mitigation using advanced technology phase I: Review, design, and implementation. Report No. FHWA-OR-TPF-07-01. Federal Highway Administration, Washington DC.

Insurance Institute for Highway Safety. (2021). Collisions with Animals. Insurance Institute for Highway Safety, Arlington, Virginia. https://www.iihs.org/topics/fatality-statistics/detail/collisions-withfixed-objects-and-animals\#collisions-with-animals. Accessed January 6, 2021.

Jiang, X., Qiu, Y., \& Lyles, R.W. (2013). Hazard assessment of deer-vehicle collisions in Michigan. Human and Ecological Risk Assessment: An International Journal, 19(4), 900-915. https://doi.org/10.1080/10807039.2012.691817.

Khattak, A., 2003. Human fatalities in animal-related highway crashes. Transportation Research Record, 1840(1). https://doi.org/10.3141/1840-18.

Langley, R.L., Higgins, S.A., \& Herrin, K.B. (2006). Risk factors associated with fatal animal-vehicle collisions in the United States, 1995-2004. Wilderness \& Environmental Medicine, 17(4), 229-239. https://doi.org/10.1580/06-WEME-0R-001R1.1.

Lao, Y., Zhang, G., Wu, Y.J., \& Wang, Y. (2011a). Modeling animal-vehicle collisions considering animalvehicle interactions. Accident Analysis \& Prevention, 43(6), 1991-1998. https://doi.org/10.1016/j.aap.2011.05.017.

Lao, Y., Wu, Y.J., Corey, J., \& Wang, Y. (2011b). Modeling animal-vehicle collisions using diagonal inflated bivariate Poisson regression. Accident Analysis \& Prevention, 43(1), 220-227. https://doi.org/10.1016/j.aap.2010.08.013.

Marcoux, A. (2005). Deer-vehicle collisions: an understanding of accident characteristics and drivers' attitudes, awareness, and involvement. Master's thesis. Michigan State University.

McCollister, M., \& Van Manen, F. (2010). Effectiveness of wildlife underpasses and fencing to reduce wildlife-vehicle collisions. The Journal of Wildlife Management, 74(8). https://doi.org/10.2193/2009-535.

Morelle, K., Lehaire, F., \& Lejeune, P. (2013). Spatio-temporal patterns of wildlife-vehicle collisions in a region with a high-density road network. Nature Conservation, (5), 53-73. http://hdl.handle.net/2268/158178.

Murphy, A., \& Xia, J. (2016). Risk analysis of animal-vehicle crashes: a hierarchical Bayesian approach to spatial modelling. International Journal of Crashworthiness, 21(6), 614-626. https://doi.org/10.1080/13588265.2016.1209823.

National Highway Traffic Safety Administration. (2015). Traffic Safety Facts 2015. National Highway Traffic Safety Administration, Washington, D.C., 2015.

Niemi, M., Rolandsen, C.M., Neumann, W., Kukko, T., Tiilikainen, R., Pusenius, J., Solberg, E.J., \& Ericsson, G. (2017). Temporal patterns of moose-vehicle collisions with and without personal injuries. Accident Analysis \& Prevention, 98, 167-173. https://doi.org/10.1016/j.aap.2016.09.024.

Riginos, C., Fairbank, E., Hansen, E., Kolek, J., \& Ham, M. (2019). Effectiveness of Night-time Speed Limit Reduction in Reducing Wildlife-Vehicle Collisions. Report No. FHWA-WY-1904F. Wyoming Department of Transportation. 
Riginos, C., Copeland, H., Smith, C., Sawyer, H., Krasnow, K., \& Hart, T., (2016). Planning-support for mitigation of wildlife-vehicle collisions and highway impacts on migration routes in Wyoming. Report No. FHWA-WY-16/10F. Wyoming Department of Transportation.

Rodríguez-Morales, B., Díaz-Varela, E., \& Marey-Pérez, M. (2013). Spatiotemporal analysis of vehicle collisions involving wild boar and roe deer in NW Spain. Accident Analysis \& Prevention, 60, 121133. https://doi.org/10.1016/j.aap.2013.07.032.

Rowden, P., Steinhardt, D., \& Sheehan, M. (2008). Road crashes involving animals in Australia. Accident Analysis \& Prevention, 40(6), 1865-1871. https://doi.org/10.1016/j.aap.2008.08.002.

SAS Institute. (2015). SAS/STAT® 14.1 User's Guide: The logistic Procedure. SAS Institute, Inc., Cary, North Carolina.

Savolainen, P., \& Ghosh, I. (2008). Examination of Factors Affecting Driver Injury Severity in Michigan's Single-Vehicle-Deer Crashes. Transportation Research Record, 2078(1). https://doi.org/10.3141/2078-03.

Sullivan, J. (2011). Trends and characteristics of animal-vehicle collisions in the United States. Journal of Safety Research, 42(1). https://doi.org/10.1016/j.jsr.2010.11.002.

Wilkins, D.C., Kockelman, K.M., \& Jiang, N. (2019). Animal-vehicle collisions in Texas: How to protect travelers and animals on roadways. Accident Analysis \& Prevention, 131, 157-170. https://doi.org/10.1016/j.aap.2019.05.030.

Wyoming Department of Transportation (WYDOT). (2021). http://www.dot.state.wy.us/home.html, accessed February 28, 2021.

Yang, X., Zou, Y., Wu, L., Zhong, X., Wang, Y., Ijaz, M., \& Peng, Y. (2019). Comparative analysis of the reported animal-vehicle collisions data and carcass removal data for hotspot identification. Journal of Advanced Transportation, 2019. https://doi.org/10.1155/2019/3521793.

Young, R., \& Vokurka, C. (2007). Relating wildlife crashes to road reconstruction. Mountain Plains Consortium, U.S. Department of Transportation, Washington, D.C.

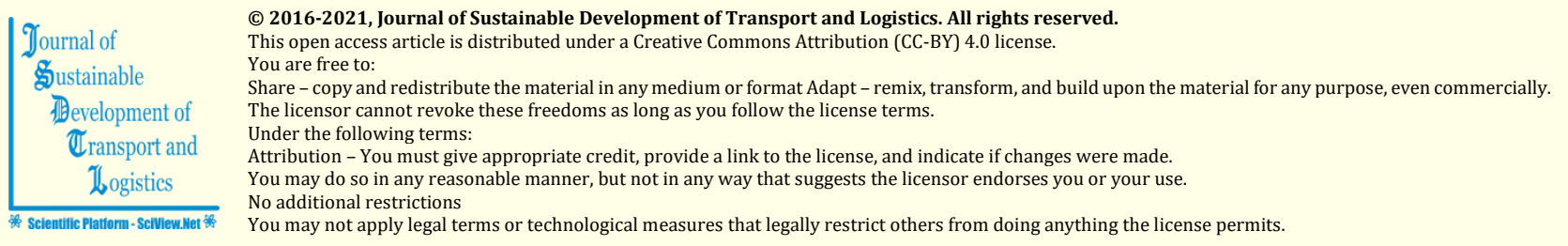

Journal of Sustainable Development of Transport and Logistics (ISSN: 2520-2979) is published by Scientific Publishing House "CSR", Poland, EU and Scientific Publishing House "SciView", Poland, EU

Publishing with JSDTL ensures:

- Immediate, universal access to your article on publication

- High visibility and discoverability via the ISDTL

- Rapid publication

- Guaranteed legacy preservation of your article

- Discounts and waivers for authors in developing regions

Submit your manuscript to a JSDTL at https://jsdtl.sciview.net/ or submit.jsdtl@sciview.net 